UDK 342.7-055.2

https://doi.org/10.18485/fb_ic4hs.2018.26

\title{
IMPACT OF THE GENDER DIGITAL DIVIDE ON SECURITY AND WOMEN'S HUMAN RIGHTS
}

\author{
Ksenija ĐURIĆ-ATANASIEVSKI*, Brankica POTKONJAK-LUKIĆ *
}

\begin{abstract}
The problem of the gender digital divide is recognized today as a problem of women's human rights, but also as a social, economic and security problem. It involves a number of international actors because it is estimated that, without progress in solving the gender digital divide, the gap between the presence of women and men in Internet communication technologies will increase, causing even greater gender differences, but also the economic, social and security vulnerability of women globally.

Unequal conditions for women and men in the economy and different economic opportunities for one or the other gender have existed for a long time, but digital technologies have made this problem even more visible and acute. Most jobs come from science, technology, engineering and mathematics (the so-called STEM), but it is estimated that in the developed world only $12 \%$ of students of technical sciences are female.

The social and economic empowerment of women, i.e. work engagement in digital technologies, diminishes their overall vulnerability. In addition to the positive economic effects, knowledge in the use of ICT increases awareness and the use of positive knowledge in other spheres of life, such as, for example, security, protection of human rights, healthcare, legal issues, environmental protection or culture.

The problem of the gender digital divide requires the consideration of the causes of gender inequality in education, of the possibilities of educating boys and girls and the availability of information literacy, but also of the causes that come from other areas such as education based on religious and ethnic postulates or prejudices about gender roles and the intellectual abilities of boys and girls. These causes may exist in the legal and political sphere, and especially in the sphere of security and protection.

The paper presents the solutions for overcoming the gender digital divide and its impact on women's lives and security. It also presents the situation in Serbia, providing data on the
\end{abstract}

\footnotetext{
* Associate professor, PhD, Department of Management, National Defence School ksenija.djuric@mod.gov.rs1

** PhD, MoD of the Republic of Serbia; brankica.lukic-potkonjak@mod.gov.rs
} 
gender digital divide and comparisons with the situation globally. Possible measures for reducing the existing differences are analyzed from the perspective of the implementation of Serbian documents and strategies for gender equality and the achievement of their goal - to increase women's security in terms of protecting their human rights more effectively.

Keywords: gender digital divide, gender equality, women's human rights, security of women

\section{INTRODUCTION}

Information and communication technologies (ICTs) have undergone similar development to other communication technologies. These new technologies have benefited those who already had access to other resources at greater rates than people who had fewer resources (de Haan, 2004; van Dijk, 2006). However, the unfolding of the digital evolution is happening at an unprecedented speed (Rogers, 2003).

The benefits of the development of ICT are undeniable in all areas of society and the lives of individuals. Those who do not use ICTs are at a disadvantage economically, socially, politically and educationally (Morahan-Martin, 2000). ICTs are seen as necessary ingredients for economic development in the so-called 'knowledge society'. Internet search, online multimedia resources, social media, as well as services such as egovernment, e-health, e-banking, e-learning, e-commerce, and e-voting, all create new arrangements of communication, engagement and social and economic behaviour (European Parliament, 2018). Nevertheless, differences have remained in Internet access, Internet use and its impact. The term "digital divide" refers to the gap between individuals, households, businesses and geographic areas at different socioeconomic levels with regard to their opportunities to access ICTs and their use of the Internet for a wide variety of activities (Organization for Economic Cooperation and Development, 2001). In academic papers and research based on different theories, the digital divide is seen as a social issue. At the level of the individual, the digital divide exists as a difference in the use of digital technologies in terms of age, place of residence, indigenous wealth, ethnic origin or belonging to one or the other sex. In that context, the available data disaggregated by sex and their analysis show that the gender digital divide affects women to a much greater extent than men. Women have traditionally been underrepresented in regard to the use and especially development of ICT. This undeniably has a negative impact on all aspects of women's lives, first of all on the protection of their human rights and security, which is an essential precondition for the individual empowerment of women and their social development in every way.

\section{WHY IS THE GENDER DIGITAL DIVIDE IMPORTANT?}

The unequal use of the Internet by men and women is an inequality that has been identified as one of the most important forms of the digital divide. The "gender digital divide (GDD)" refers to the measurable gap between women and men in their access to, use of and ability to influence, contribute to and benefit from ICTs (Human Right Council UN, 2017). The International Telecommunication Union (ITU) has described the GDD as 
a gender-driven imbalance in access to ICTs, general ICT literacy and presence in science, technology, engineering and mathematics studies (ITU, 2012).

The differences between male and female ICT users are of increasing interest worldwide as the digital divide evolves. The GDD is more prominent in the developing world, where $80 \%$ of the world's population of women lives, but it still exists in the developed world. According to the International Telecommunication Union (ITU, 2016), "the global Internet user gender gap grew from $11 \%$ in 2013 to $12 \%$ in 2016 ".

Gender-based discrimination and disparities in the physical world are being replicated in the digital world (Federal Ministry for Economic Cooperation and Development of Germany, 2017). Barriers such as the cost, network coverage, security and harassment, trust and technical literacy, language barriers and barriers to women speaking freely and privately online all contribute to the fact that women in developing countries are nearly $25 \%$ less likely to be online than men (Intel Corporation, 2018).

In a study titled Gender and Digital Agenda, the European Institute of Gender Equality (EIGE, 2016) provides an overview of gender inequality issues in digitalization and identifies gender differences not only in access to and use of digital technologies, but also in digital-related education and other fields of study between girls and boys, in women's low participation in the digital labour market and in the impact of cybercrime on women. The digital divide can be understood as the existence of inequalities in four successive types of access: motivation, physical access, digital skills and different usage. It is claimed that the divide has shifted from the first to the last-called type of access in the last ten years (van Dijk, 2012). The offline population is disproportionately poor, rural, older and female, and the gap between them and those who have access to the Internet is widening steadily. Worldwide, it is estimated that approximately 250 million fewer women than men are online (Philbeck, 2017). The development of mobile telephony has made access to the Internet easier. However, there are still 200 million fewer women than men who have access to mobile phones in developing countries. Women's access to ICT is constrained by factors that go beyond issues of technological infrastructure: socially and culturally constructed gender roles shape and limit the capacity of women and men to participate on equal terms.

There is also an inequality in Internet use between men and women. Some researchers believe that more men than women use the Internet because of gender differences in socioeconomic status, some explain this as gender differences in gender roles and others still as gender-influenced perception of computer technology (Hafkin, 2013). The education of boys and girls is based on the creation of gender roles which are the result of social expectations and stereotypes in many societies. It is believed that boys are more interested in ICT (Faulkner, 2001, Nsibirano, 2009). The research of Livingstone and Helsper (2007) confirms that there are no gender differences in computer usage among younger children (7-11 years) but that the gender gaps expand significantly in their mid-teens (16-17) - by then, boys use the Internet more frequently and perform a wider range of activities than girls. Women need to have the knowledge and resources to translate access into effective use (Human Rights, Big Data and Technology Project, 2016). It is necessary to have digital literacy and digital competence. Men use the Internet more than women for a wide range of activities, particularly those that require greater technological skills such as job 
searching, e-banking, and posting or uploading material, while women like it for the human connections it promotes (Fallows, 2005). Other reasons for the gender inequality in the use of ICT are socio-cultural barriers such as the patriarchal system in many developing countries that only allows women (unpaid) household work and impedes schooling. In developed countries, women can also be unemployed or burdened with the "triple burden" - work, home and community.

ICTs are increasingly being recognized for their potential to carry the new global knowledge-based economy. The ICT market itself presents many opportunities for growth through the development of software products for a variety of purposes, the expansion of social media and other large corporate platforms, the development of news goods and services, the evolution of artificial intelligence and the Internet of Things, or 'green growth' and the increasing demand for smart applications (ITU, 2012). ICTs also enable work from home, which is extremely important for women and their families.

The delay of women in digital education has led to an increase in the gender gap even in developed countries. In the world of information technology and computer science, men dominate not only numerically, but also in regard to their positions. Women in ICTs occupy low-level jobs and represent only $19.2 \%$ of managers in the ICT sector, compared to a much better share of $42.5 \%$ in the non-ICT service sector (European Parliament, 2018). The study Women in ICT explains this low representation of women in terms of stereotypes about women lacking relevant skills (including leadership skills and aptitude for STEM studies and careers); work-life balance complexities; male stereotypes and networking culture; and lack of role models.

While the use of ICTs has contributed to the empowerment of women and to a fuller realization of their human rights, it has also facilitated the development of online violence against women. The General Assembly of the UN acknowledged in its Resolution 68/181 that information technology-related violations, abuses and violence against women were a growing concern and could be a manifestation of systemic gender-based discrimination, requiring effective responses compliant with human rights. Online violence against women encompasses acts of gender-based violence that are committed, facilitated or aggravated by the use of ICTs, including online threats and harassment and gross and demeaning breaches of privacy, such as "revenge pornography" (Women's Rights Online, 2015). Online violence has risen sharply over the past few years and can result in women limiting their participation on online platforms.

Such a situation should not lead to the conclusion that women should use ICT less. It is the responsibility of administrators, sites and platforms whose content could be classified as cybercrime to fight against online violence. Also, every empowerment of women and their increasing percentage in ICT proportionally empower their human rights.

\section{HOW TO OVERCOME THE GENDER DIGITAL DIVIDE}

Measures, activities and proposals for the solution of the gender digital gap are offered by numerous governmental and non-governmental organizations. Realization is largely left to national states. Solutions to the GDD problem are based on the fact that the gender gap goes beyond the nature of technology. Policies that only attempt to improve women's access to and more frequent use of digital technologies cannot solve the problem of the 
gender split. They have to respect the political, economic or sociocultural factors that create the inequality of women in societies and improve their human rights. The technology and the Internet are not agents of change by themselves, but they encompass gendered characteristics and interact with social circumstances in complex ways. The aim of policy and practice is that the outcomes of such interactions work toward greater gender equality. Nonetheless, the settings in which ICTs are often placed might reproduce such inequalities or recast them in new forms as well (European Parliament, 2017).

Most of the proposals stem from the fact that overcoming or at least reducing the gender digital gap would have economically quantitative effects. The European Commission Report (2013) concludes that if as many women as men held jobs in the digital economy, this could boost the annual EU GDP with roughly EUR 9 billion. In addition to the economic advantages, numerous other benefits are also derived from greater and better involvement of women in ICT. The GDD is both a consequence and cause of violations of women's human rights. It is a consequence in that disparities in ICT access and use reflect the discrimination of women in society. The GDD is also a cause of violations of women's human rights: women without meaningful ICT access are less equipped to exercise their human rights and to participate in public life, the economy and society (United Nations High Commissioner for Human Rights, 2017).

A systematic approach to embedding human rights in efforts to tackle the GDD requires addressing the full range of women's human rights that are affected by ICTs. Inequalities in access to and use of the Internet and associated technologies have the potential to undermine the opportunities for realising human rights and attaining the Sustainable Development Goals (SDGs) as ICTs may function as a gateway to the realisation of human rights (Human Rights, Big Data and Technology Project, 2016). Women who have access to ICT equipment and who are confident, skilled and capable of using it efficiently have been given an extremely valuable opportunity to contribute to their economic, social and political empowerment. Thereby, they can also be better aware of their legal rights and have a significant impact on improving the quality of their lives and increasing their personal safety and security. Today, communication through social media, mobile phone applications and websites is a powerful means of enabling women, inter alia, to raise their awareness of gender equality, different types of gender-based violence, and penalties for non-compliant behaviour. It also enables women to exchange experiences through networking, to report security risks and get in touch with adequate services that can support and help them in cases of any kind of abuse and violations of their human rights. On the other hand, it is more and more evident that using ICT has the potential to encourage new online risks and forms of violence against women and this is something women must be fully aware of.

There are several documents from international organizations that propose activities for closing the GDD. Some of them are: the Sustainable Development Goals (UN, 2015), the Action Plan in the ITU Report of the United Nations High Commissioner for Human Rights. The UN Sustainable Development Goals list the major goals that a country needs to achieve in order to overcome the GDD. UN Member States are required to: achieve universal affordable internet access by 2020 (SDG target 9.c); ensure equal access to basic services [and] appropriate new technology for all women and men (SDG target 1.d); implement policies to empower women through technology (SDG target 5.b). Beyond 
these important targets, access to ICT is also critical to achieving other SDGs, such as: achieving quality education (Goal 4), creating decent work and economic growth (Goal 8) and reducing inequalities (Goal 10).

In 2014, the International Telecommunication Union (ITU) adopted an action plan to accelerate inclusive and sustainable development by closing the digital gender gap and harnessing the transformative potential of ICTs for women's empowerment. It can be understood as potentially challenging and changing the power relations between men and women and as enabling women to take greater control over their resources and lives in general. The broad aims of the Action Plan are: 1. Develop gender-responsive strategies and policies 2. Ensure access to ICTs by women and mitigate the online risks that hinder women's access to and use of technology 3. Build digital capacities and support development of content, applications and services that meet women's needs 4 . Promote women in the technology sector, including in positions of decision-making 5. Establish multi-stakeholder partnerships.

\section{THE GENDER DIGITAL DIVIDE IN SERBIA}

Bearing in mind that the GDD is an inequality between men and women in the access, use and impacts of ICTs, statistical data in Serbia suggest that there is no gender digital gap for two of the three factors - access to and use of ICTs. According to data from 2016, the majority of users are women, and in most age groups more women than men are information literate.

However, when it comes to education, employment and the IT sector, statistics reveal that men have an advantage. In information technology, $74 \%$ of graduates in Serbia are men, compared with $88 \%$ of male students in some developed countries. A smaller percentage of women in ICT will determine a smaller number of women in all innovative economic branches that will develop from IT in the future.

In recent years, the Serbian government and relevant ministries have recognized the importance of increasing women's digital competencies and their participation in ICT considering that these jobs will be the most promising and well paid in the future. The importance placed on overcoming the GDD is also reflected in the fact that the celebration of the ICT Girls Day started in April 2010 at the initiative of Serbia.

The 2017-2020 Strategy for the Development of Information Technologies Industry, as well as the 2018 action plans for the implementation of the strategy envision many activities related to the GDD, such as: introducing information science in elementary schools; projects and programmes for the re-education of women that would enable them to be employed in the ICT sector or start their own business through start-up companies.

\section{CONCLUSION}

The GDD is recognized in politics, science and practice as one of the major problems in respecting women's human rights, but also as a developmental problem affecting all segments of society. Therefore, reducing the gender digital gap will positively contribute to economic, political and security development. In Serbia, the percentage of women who use ICT and are digitally literate is more favourable than in some developed countries. Although the percentage of women employed in the information industry is also higher 
compared to some other countries, the situation is not favourable. It is necessary to undertake measures for empowering women in ICT as the technology of the future.

\section{REFERENCES}

Akcioni plan za 2018 za sprovodjenje Strategije razvoja industrije informacionih tehnologija 2017-2020 (in Serbian): Retrieved from http://www.srbija.gov.rs/vesti/dokumenti sekcija.php?id=4567

Amy,A, Tuffley D.(2014). The Gender Digital Divide in Developing Countries, Future Internet. 6(4), 673-68.doi10.3390/fi6040673

Broadband Commission (2013). Doubling Digital Opportunities: Enhancing the Inclusion of Women and girls in the Information Society. Retrieved from http:/www.broadbandcommission.org/documents/working-groups/bb-doublingdigital 2013.pdf

de Haan, J. (2004). A multifacte dynamic model of the digital divide. IT\&Society. 1(7), p 66-88

Digging into Data on the Gender Digital Divide (2016) Web Foundation, Retrieve from https://webfoundation.org/2016/10/digging-into-data-on-the-gender-digitaldivide/

Dighe, A and U. Reddi (2006) Women's Literacy and Information and Communication Technologies: Lessons that Experience has Tought us. Commonwealth Educational Media Centre for Asia, p.4.

European Parliament's Policy Department for Citizens' Right and Constitutional Affairs, Directorate General for Internal Policies (2018). The Underlying causes of the digital gender gap and possible solutions for enhanced digital inclusion for women and girls. PE 640.940

European Parliament (2012) Women in ICT. Brussels: Policy Department C - Citizens' Rights and Constitutional Affairs Brussels: European Parliament.

European Commission (2013) Women Active in the ICT Sector. Brussels: European Commission.

Fallows, D. (2005) How Women and Men Use the Internet. Pew Research Center. Internet and Technology. Retrieved from http://www.pewinternet.org/2005/12/28/howwomen-and-men-use-the-internet/

Faulkner, W.(2001). The technology question in feminism: A view from feminist technology studies. Women's Studies International Forum.24(1)

Gender and Digital Agenda.(2016) Luxemburg: European Institute for Gender Equality.

Hafkin, N. (2013) Stocktaking and Assessment on Measuring ICT and Gender for the Partnership on Measuring ICT for Development. Task Group on Gender of the Partnership on Measuring ICT for Development, p.11. )

Hilbert, M. (2011). Digital gender divide or technologically empowered women in developing countries? A typical case of lies, damned lies, and statistics. Women's $\begin{array}{llll}\text { Studies International } & \text { Forum, } & \text { 47(6), }\end{array}$ http://dx.doi.org/10.1016/j.wsif.2011.07.001

Human Rights Big Data and Technology Project (2016). Ways to bridge the Gender Digital Divide from a Human Rights Perspective, Human Rights Center of the University of Essex 
International Telecommunication Union (2012). A Bright Future in ICT: Opportunities for a New Generation of Women. Geneva: International Telecommunications Union. Retrieved from https://www.itu.int/en/ITU-D/Digital-Inclusion/Women-andGirls/Documents/ReportsModules/ITUBrightFutureforWomeninICTEnglish.pdf.)

International Telecommunication Union \& UN Women (2015). Action Plan to Close the Digital Gender Gap. Retrieved from https://www.itu.int/en/action/genderequality/Documents/ActionPlan.pdf

International Telecommunication Union "The gender digital inclusion map: research methodology" Retrieved from https://www.itu.int/en/action/genderequality/PublishingImages/Pages/EQUALS/The\%20Gender\%20Digital\%20Inclus ion\%20Map\%20-\%20Research\%20Methodology.pdf

Livingstone, S, Helsper, E. (2007). Gradations in digital inclusion: children, young people and the digital divide. New media \& society, 9 (4). pp. 671-696. DOI: $10.1177 / 1461444807080335$

Morahan-Martin, J. (2000) Women and the Internet: Promise and Perils. Cyber Psychology and behaviour, Volume 3 No 5: 683-691

Nsibirano, R. (2009). "Him and Her" - Gender differentials in ICT uptake: A critical literature review and research agenda. International Journal of Education and Development using Information and Communication Technology (IJEDICT), 2009, Vol. 5, Issue 5, pp.33-42.

Philbeck, I- (2017). Connecting the unconnected: working together to achieve Connect 2020 Agenda targets, background paper to the special session of the Broadband Commission and the World Economic Forum at the Davos Annual Meeting 2017, p. 7

Rogers, E. M. (2003). Diffusion of Innovations, 5th Edition (5th ed.). Free Press.

Understanding the Digital Divide, Organization for Economic Cooperation and Development, (2001)

van Dijk, J.A. (2005) The Deepening Divide: Inequality in the Information Society (1st ed) Sage Publication, Inc.

van Dijk, J.A. (2012) The Evolution of the Digital Divide. Digital Enlightenment Yearbook 201 2J. Bus et al. (Eds.) IOS Press, 2012 doi:10.3233/978-1-61499057-4-57

Women and the Web. (2018). Intel Corporation \& Dalberg Global Development. Retrieve on 23. June 2018 from

https://www.intel.com/content/dam/www/public/us/en/documents/pdf/womenand-the-web.pdf

Women's Pathways to the Digital Sector: Stories of Opportunities and Challenges (2017), Federal Ministry for Economic Cooperation and Development of Germany. Retrieved from https://www.itu.int/en/ITU-D/Digital-Inclusion/Women-andGirls/Girls-in-ICT-Portal/Pages/Publications.aspx

Women`s Right Online: Translating Access into Empowerment (2015). Webfounation. Retrieved from http://webfoundation.org/docs/2015/10/womens-rightsonline21102015.pdf 